\title{
Giant hydronephrosis due to ureteropelvic junction obstruction: A rare case report, and a review of the literature
}

\author{
QI-FEI WANG ${ }^{1}$, GUANG ZENG $^{2}$, LIN ZHONG ${ }^{3}$, QUAN-LIN LI ${ }^{1}$, XIANG-YU CHE ${ }^{1}$, TAO JIANG ${ }^{1}$, \\ ZHI-WEI ZHANG ${ }^{1}$, WEI ZHENG ${ }^{1}$, QI-ZHEN TANG ${ }^{1}$, FENG CHEN $^{1}$ and KE-NAN WANG ${ }^{1}$ \\ ${ }^{1}$ Department of Urology, The First Affiliated Hospital of Dalian Medical University, Dalian, Liaoning 116000; \\ ${ }^{2}$ Training Office of Graduate School of Dalian Medical University, Dalian, Liaoning 116044; ${ }^{3}$ Department of Pathology, \\ The First Affiliated Hospital of Dalian Medical University, Dalian, Liaoning 116000, P.R. China
}

Received August 21, 2015; Accepted October 26, 2015

DOI: $10.3892 / \mathrm{mco} .2016 .876$

\begin{abstract}
The hydronephrotic kidney, resulting from a ureteropelvic junction obstruction (UPJO), presents commonly as a clinical condition, with the presence of usually no more than 1-2 liters in the collecting system, but a very small number of cases of giant hydronephroses (GHs) has been reported in adults. A GH is defined as the adult renal pelvis containing $>1$ liter of urine, or at least $1.5 \%$ of the body weight. In the majority of cases, the range of the hydronephrotic kidney remains restricted to the renal area. However, the patient described in the present case report had a range for the hydronephrotic kidney which occupied almost the entire abdominal cavity ( 241$)$, and cases such as these are rarely presented; therefore the aim of the present case study was to document a clear case of GH resulting from UPJO, also accompanied by a review of the current literature.
\end{abstract}

\section{Case report}

An 18-year-old woman patient was admitted to hospital with complaints of abdominal distension, and the patient had experienced intermittent mild abdominal pain since birth. The abdominal girth had slowly increased in diameter over the previous 18 years, and the patient's general condition of health was poor, presenting symptoms including fatigue, fever, nausea, vomiting, decreased appetite and weight loss. No specific urinary or bowel dysfunction was identified. Clinically, the diagnosis of a giant hydronephrose $(\mathrm{GH})$ was made, and upon physical examination, an extremely distended abdomen was revealed, with a palpable mass in the all-flank region (Fig. 1A). Bowel sounds could not be auscultated, and

Correspondence to: Dr Qi-Fei Wang, Department of Urology, The First Affiliated Hospital of Dalian Medical University, 222 Zhongshan Road, Dalian, Liaoning 116000, P.R. China

E-mail: frog080619@163.com

Key words: giant hydronephrosis, ureteropelvic junction obstruction (UPJO) neither was there any shifting dullness. An examination of the other systems failed to disclose any noteworthy phenomena.

The blood laboratory analyses revealed a concentration of blood urea nitrogen of $30.1 \mathrm{mg} / \mathrm{dl}$, and a level of creatinine of $1.56 \mathrm{mg} / \mathrm{dl}$. The level of hemoglobin was $12 \mathrm{~g} / \mathrm{dl}$, and the hematocrit was determined to be $45.7 \%$, whereas tumor markers were all revealed to be in normal range, The results of the urine analysis revealed a red blood cell count of $32 /$ high power field (HPF) a white blood cell count of $6 / \mathrm{HPF}$ and a yeast cell count of 5/HPF. Blood sugar, phosphate, liver function, serum calcium, serum amylase and electrolyte analyses all yielded results within the normal limits. A diagnostic aspiration performed from the area of abdominal swelling revealed the presence of urine. Ultrasonography revealed the presence of a massive hypoechoic lesion occupying almost the entire abdomen, which exerted pressure on the bowel on the left-hand side. The left kidney appeared normal, although the right kidney could not be identified. A cystic lesion revealed multiple septations, which were likely to have arisen from the right kidney. A computerized tomography (CT) scan revealed a large abdominal mass of water density in the all-abdomen area, which comprised a huge cystic mass $(41.5 \times 30.5 \times 30.5 \mathrm{~cm}$; Fig. 2A-C) that, in the right kidney, occupied almost the entire abdominal cavity. This mass had displaced the small intestine, colon, pancreas, spleen and the left kidney. After admission, the cystic mass was punctured, and a total of $\sim 241$ urinal fluid was drained by urethral catheterization over a period of 8 days (3 liters each day). There was an improvement in the general condition of the patient: The distended abdomen decreased in size (Fig. 1B), the level of urea declined to $1.42 \mathrm{~g} / 1$, and the level of creatinine was $63 \mathrm{mg} / \mathrm{l}$. The results of subsequent laboratory analyses and urine culture were normal. A subsequent CT scan revealed an almost complete disappearance of the hydronephrosis (Fig. 2D). A right nephrectomy was performed: When an incision was made in the right lumbar region, the cyst presented as a retroperitoneal soft cystic dilatation mass, lacking in definition, measuring almost 30x20x15 cm (Fig. 3), which was able to adhere to adjacent organs, including the liver and the pelvic cavity, lifting the cecum and the ascending colon. The ureter was normal, and ureteropelvic junction obstruction (UPJO) was established as the cause of GH. The pathological tissue sections are shown in Fig. 4. 
Table I. List of documented cases of GHs reported in the literature of the present study.

\begin{tabular}{|c|c|c|c|c|c|c|c|}
\hline $\begin{array}{l}\text { Patient } \\
\text { no. }\end{array}$ & Year & $\begin{array}{l}\text { Age/ } \\
\text { gender }\end{array}$ & Refs. & $\begin{array}{l}\text { Size of mass }(\mathrm{cm}) / \\
\text { quantity of fluid }(\mathrm{ml})\end{array}$ & $\begin{array}{l}\text { Initial } \\
\text { symptoms }\end{array}$ & Treatment & Cause of GH \\
\hline 1 & 2009 & $65 / \mathrm{F}$ & (1) & $30 \times 20 \times 25 / 15,000$ & Fatigue, fever & Nephrectomy & Obstruction \\
\hline 2 & 2003 & $78 / \mathrm{F}$ & (2) & $35 \times 30 \times 25 / 30,000$ & $\begin{array}{l}\text { Nausea, vomit, } \\
\text { fatigue, fever, } \\
\text { weight loss }\end{array}$ & $\begin{array}{l}\text { Puncture/drainage, } \\
\text { nephrectomy }\end{array}$ & Tumor \\
\hline 3 & 2012 & $42 / \mathrm{M}$ & (3) & $44 \times 32 \times 30 / 20,000$ & Weight loss & Nephrectomy & $\begin{array}{l}\text { Bladder neck } \\
\text { obstruction }\end{array}$ \\
\hline 4 & 2013 & $82 / \mathrm{M}$ & (4) & $30 \times 21 \times 10 / 4,500$ & Fever & Nephrectomy & Tumor \\
\hline 5 & 2009 & $45 / \mathrm{M}$ & $(5)$ & $30 \times 20 \times 20 / 15,000$ & $\begin{array}{l}\text { Anemia, liver } \\
\text { dysfunction }\end{array}$ & Nephrectomy & Stone \\
\hline 6 & 2014 & $83 / \mathrm{M}$ & (6) & $20 \times 16 \times 22 / 4,000$ & $\begin{array}{l}\text { Fatigue, nausea, } \\
\text { vomit, weight } \\
\text { loss }\end{array}$ & $\begin{array}{l}\text { Puncture/drain } \\
\text { nephrectomy }\end{array}$ & Ureteral stone \\
\hline
\end{tabular}

M, male; F, female; GH, giant hydronephrosis.
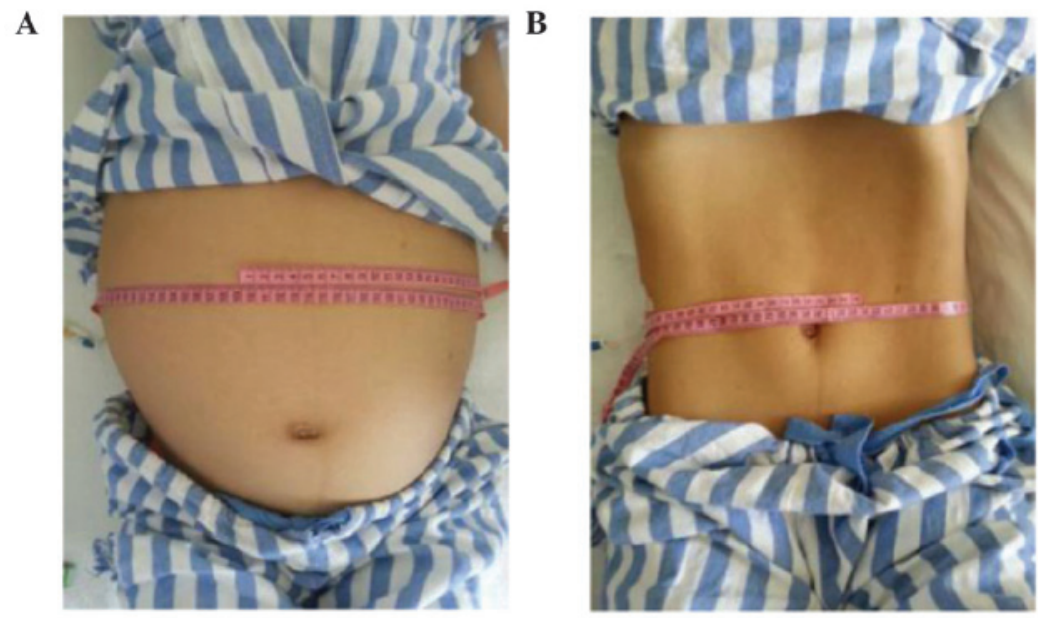

Figure 1. (A) Preoperative photograph of the patient showing the grossly distended abdomen caused by GH of the right kidney. (B) Postoperative photograph of the patient following nephrectomy of the affected side.

\section{Discussion}

$\mathrm{GH}$ is a rare urological condition, which occurs in patients of all ages, defined as the presence of $>1$ liter of fluid in the collecting system (1). It is considered to develop gradually over a long period of time. Symptomatic nephrolithiasis and hydronephrosis more frequently present as clinical conditions, and $\mathrm{GH}$ is a rare clinical phenomenon. Although numerous cases of $\mathrm{GH}$ have been reported in the literature, only a few of them contained $>2$ liters of fluid (Table I). In the present case report, the hydronephrotic kidney contained 241 urine, and GHs seldom fill the entire abdomenal space, as had occurred in our patient. The most common cause of $\mathrm{GH}$, as detailed in the literature, is a condition caused by UPJO, although stone disease, trauma, renal ectopy and ureteral tumors have also been reported (2). In the present study, UPJO was the cause of GH.

The clinical symptoms of GH are non-specific, and may present with vague symptoms, including an increased abdom- inal girth due to the presence of a mass in the flank. GH is a slowly progressive disease, and a huge abdominal mass or distended abdomen may cause pain, and be symptomatic of hematuria, recurrent urinary tract infection or other symptoms or complications described in the literature, including nausea, fatigue or dyspepsia, urinary tract infection, loss of weight, renal insufficiency, gross hematuria resulting from trauma in the area, the compression of surrounding structures, or even rupture of the kidney (3). Ultrasonography and CT scans have facilitated the diagnosis of hydronephrosis, and a case of GH may be defined as the presence of hydronephrosis occupying a hemiabdomen, which meets, or extends beyond, the midline, and which extends at least five or six vertebral bodies in length (4). However, in a number of cases, a differential diagnosis between $\mathrm{GH}$ and other cystic formations proves to be difficult. Therefore, as demonstrated in the present case report, an accurate diagnosis of GH in individual cases remains challenging. Contrast-enhanced CT of the abdomen 
A
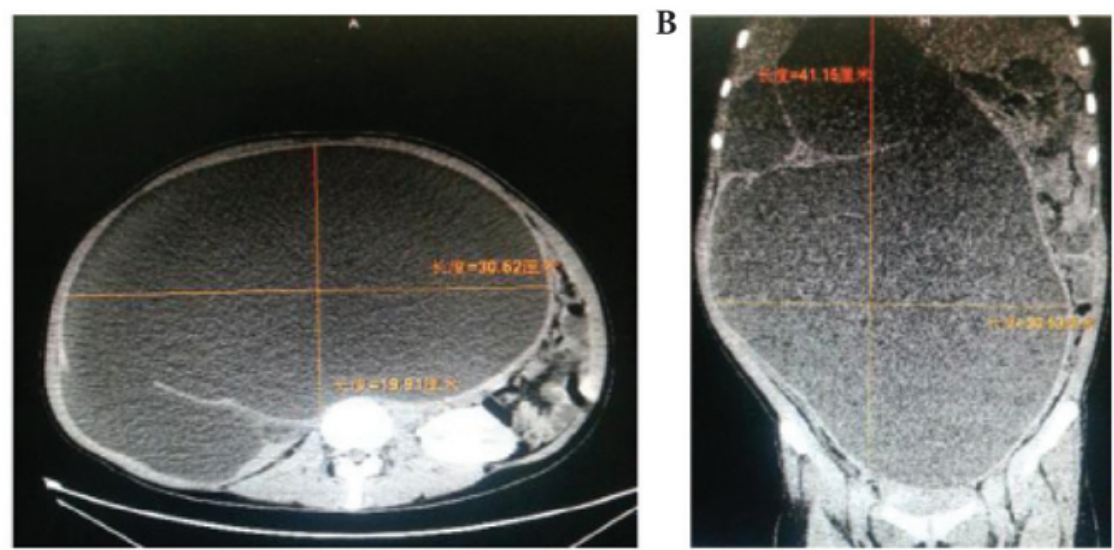

C

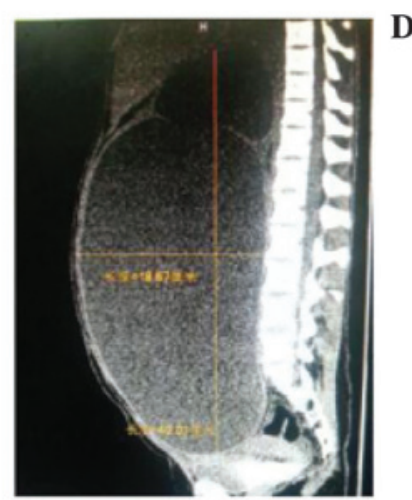

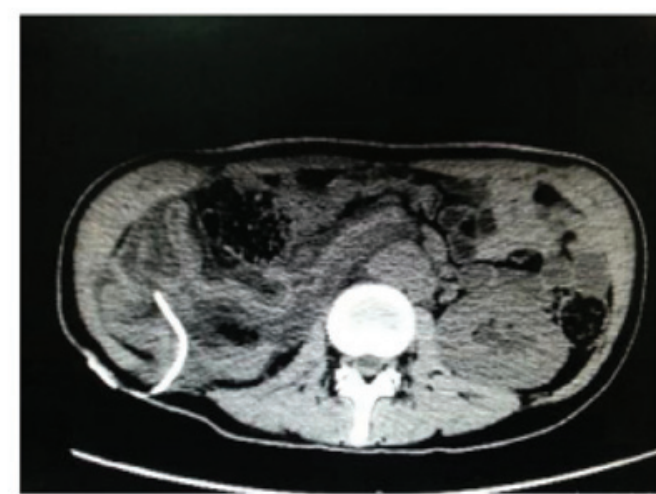

Figure 2. (A) CT scan of a GH of the right kidney (30.6x19.9 cm; transverse section). (B) CT scan of a $\mathrm{GH}$ of the right kidney (41.1x30.5 cm; coronal section). (C) $\mathrm{CT}$ scan of a GH of the right kidney (40.0x18.6 cm; vertical plane). (D) CT scan of a GH of the right kidney following drainage by urethral catheterization. $\mathrm{CT}$, computerised tomography; $\mathrm{GH}$, giant hydronephrosis.

A

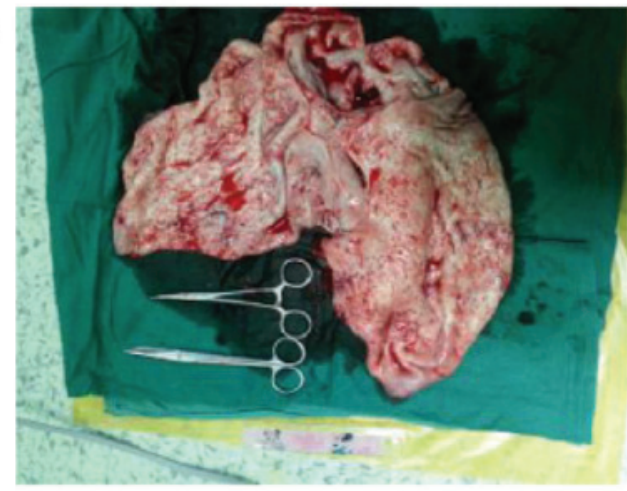

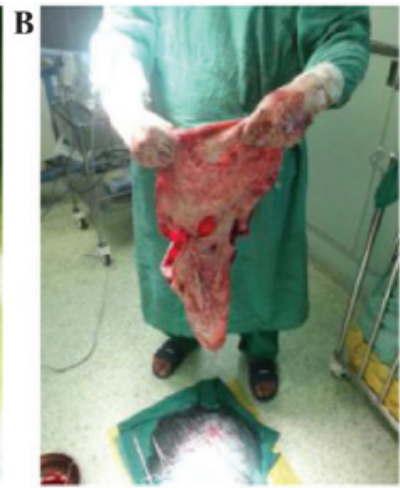

Figure 3. (A) Close-up photograph of the cystic dilatation kidney following surgery. (B) Gross photograph of the cystic dilatation kidney following surgery.

A

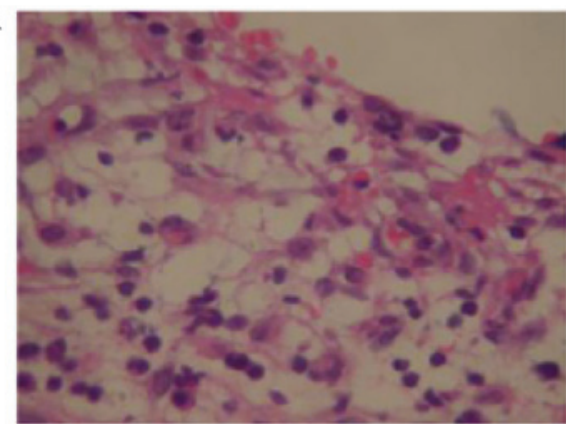

B

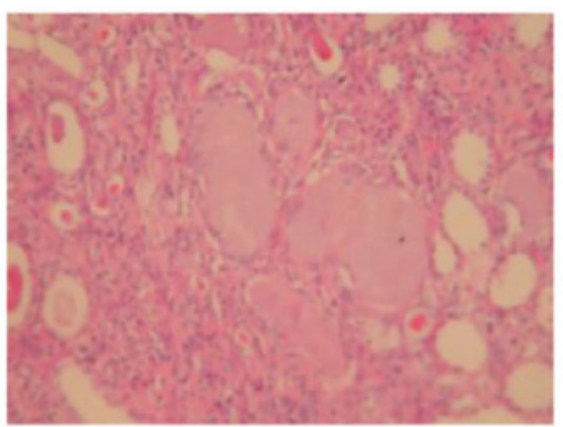

Figure 4. (A) Pathological section from the right kidney (H\&E staining, magnification, $x 400$ ). (B) Pathological section from the right kidney (H\&E staining, magnification, x200). H\&E, hematoxylin and eosin. 
and the pelvis provides the 'gold standard' for an accurate diagnosis of $\mathrm{GH}$, and other useful diagnostic imaging techniques include abdominal radiography and intravenous urography. The ideal treatment for GH is nephrectomy, and this is the procedure of choice; other treatment options in a functional kidney include percutaneous nephrostomy, reduction pyeloplasty with nephropexy calycoureterostomy, and calycocystostomy (5). In spite of the widespread use of prenatal ultrasound and the development of new diagnostic techniques, $\mathrm{GH}$ is encountered in all age groups. A puncture/drainage procedure may be performed in cases where the condition of the patient does not allow other treatments to be performed, or where hemodynamic changes may occur following a sudden abdominal decompression (6). In the present case study, the patient underwent a right nephrectomy and was discharged on postoperative day 8 . In conclusion, $\mathrm{GH}$ is a rare condition, which is associated with the occurrence of cystic abdominal masses, and the puncture/drainage procedure or nephrectomy provides the most suitable method for surgical intervention.

\section{References}

1. Vishwanath M, Pattanshetti MK, Swamy SI, Godhi, AS and Metgud, SC: Giant hydronephrosis. Indian J Surg 72: 359-360, 2009.

2. Schrader AJ, Anderer G, von Knobloch R, Heidenreich A and Hofmann R: Giant hydronephrosis mimicking progressive malignancy. BMC Urol 3: 4, 2003.

3. Tazi MF, Riyach O, Ahallal Y, Mellas S, Khallouk A, El Fassi MJ and Farih MH: Giant urinary bladder and bilateral giant hydronephrosis due to bladder neck obstruction: One case report and literature review. Case Rep Urol 2012: 817519, 2012.

4. Mediavilla E, Ballestero R, Correas MA and Gutierrez JL: About a case report of giant hydronephrosis. Case Rep Urol 2013: 257969, 2013.

5. Wu CC and Sun GH: Giant hydronephrosis. Mayo Clin Proc 84: 954, 2009.

6. Golcuk Y, Ozsarac M, Eseroglu E and Yuksel MB: Giant hydronephrosis. West J Emerg Med 15: 356, 2014. 